\section{TEACHING ORAL COMMUNICATIONS TO BUSINESS AND PROFESSIONAL STUDENTS}

\section{E.J. (Betty) Urquhart}

Effective speaking before groups usually means an effective or improved professional and social life. That's a good reason why Fraser Valley College has offered, in recent years, a course in Oral Communications, or effective speaking, at one of its main campuses each semester, and a good reason why registration in the course is growing each year.

Oral Communications 368 , a one-semester course initiated at Fraser Valley College by communications faculty member Wendy Burton, is now required in the Fashion Merchandising division of the College's Business Management Program, transferable to the Chartered General Accountants Program, and recommended for other College programs. Since it has no pre-requisites, it is scheduled in the evening to be available to interested business or professional people of the community, as well as to full-time students.

\section{Introductions and Basic Speaking Techniques}

The course begins with an evening of introductions - to the course, to the text, to the instructor, to a few communication theories, and to fellow students. Before the evening is over, each class member will have met and interviewed others in small groups, and will have made his or her first oral presentation by introducing one other student to the whole class. During the next several weeks, the students learn and practise techniques in deep breathing for relaxation, pronunciation and articulation, voice production and projection, and dealing with stage fright. To assist with this training, professional actress and part-time instructor in the College Theatre Program, who can emphasize both the physiological and the performance aspects of effective speaking, has been guest lecturer.
Students have enthusiastically received this visitor.

For this occasion, the class can be taught how to introduce and thank a guest speaker, and students are responsible for these tasks from then on. They may also get practice by introducing each other formally later on when the prepared speeches are given.

\section{Early Speeches}

Also during these early sessions, students practise their breathing exercises, do choral reading, and present one-to-two minute impromptu speeches on topics of present interest, like current affairs, with subjects usually generated by class members. These exercises assist students in feeling comfortable with the sound of their voices speaking aloud, and with standing up in front of people to speak. As well, in these first few weeks, tudents make two short prepared speeches: a one-minute memorized speech, and a two minute manuscript, or written-and-read, speech. These serve two purposes. The first is, ofcourse, to gain experience, but the second purpose is to give the class members the opportunity to see and feel what these two speaking methods are like. Obviously, with read or memorized speeches, there is little or no rapport with the audience; thus, students realize from experience the importance and value of learning to speak exxtemporaneously, using only reminder notes on cards, and they work harder to achieve this goal

\section{The First Formal Speech}

By the fifth or sixth week, students have also learned and, hopefully, put into practice procedures for developing a speech: doing audience analysis, choosing a topic, finding an attention-getter, organizing the body, using an introduction and conclusion, and preparing note cards. They have been taught listening skills as well. Then it is time for an 
evening of the first formal presentations. The videotape camera and monitor are set up at the back, the lectern is ready up at the front, and nervous class members try to remember how to make fright work for them. Throughout the course, the video camera and monitor become part of the classroom fixtures, so that students become comfortable with the equipment, and can see themselves performing frequently. In addition, as much time as possible is spent during the course in impromptu work with video, for this gives students opportunities to experience standing up front and speaking without the added pressure of having to prepare or of being marked. In most classes, after the first few weeks, impromptu speaking becomes anticipated and enjoyed, as most students likediscussing topics with other class membersin the relaxed style ofimpromptu sessions. These sessions make the formal peeches seem less formidable.

The first formal speech is a demonstration or exposition of about five minutes, in which students must tell how to do something, be it making a pie, changing a tire, giving cardio-pulmonary resuscitation, or some other skill familiar to them. Usually nervousness prevents students from achieving competent delivery style in this first presentation, but all class members manage to walk up to the front and say most, if not all, of what they planued.

\section{Evaluations: A Valuable Learning Tool}

During the course, much emphasis is placed on evaluation, as students learn a great deal through seeing the strong and weak points in others presentations as well as their own. Self-evaluation is begun with the first speech; students view themselves on videotapes outside of class time, and write evaluations of their own performance. They must also evaluate two or three other students in class each time formal speeches are presented. One evaluation is handed in for marks, but all peer evaluations are signed and given to the student being evaluated. other written assiguments are done throughout the course, many in conjunction with the study of the text. Presently at Fraser Valley College we are using Speaking the Speech, 2nd edition, by Edwin Cohen, published by Holt, Rinehart, and Winston an easily read, but reasonably comprehensive book. Handouts from other sources are used extensively as well. Written assignments, as well as the one- and two-minute speeches and later group assiguments, make up $40 \%$ of the final mark, and include exercises from the text, formal speech outlines and notes, selfevaluations, and evaluations of peers' and guests'speeches. Marks for the three formal speeches rake up $60 \%$ of the final grade, with each speech weighted more heavily than the previous one.

\section{Guest Speakers Assistance}

About halfway through the course, an outside speaker comes to give a prepared informative speech. Speakers who are willing to act as guinea pigs may be found from among other faculty members or from local resources like political candidates, or members of Toastmasters Clubs, who speak to community groups as part of their training, and to mark levels of achievement. As many guest speakers as can be found may be invited, but at least three guests come and are evaluated.

Preferably, the speaker at this stage of the course should not be too expert, so that students are not discouraged by a very professional style. The guest speakers are usually willing to stay and talk with the class about effective speaking, and add much to the program by presenting a new or different approach to the subject.

\section{The Second Formal Speeches}

By the ninth or tenth week, the second major oral presentation is due 
Now the students choose subjects about which they are knowledgeable, and give an eight minute informative speech, using at least one visual aid, such as a poster, a picture, an overhead transparency, or a chalkboard

diagram. Generally with this speech, the instructor sees a marked improvement in the technique of students' oral presentations. Having spoken formally or informally a number of times themselves, as well as having heard and evaluated other speakers, class members have assimilated and begun to incorporate into their speeches many of the techniques whose use separates the trained from the untrained speaker.

\section{Speaking in Groups}

In the last third of the semester, some experimental training in group interaction is scheduled, in the form of a meeting assignment. Reading on the group process is assigned in preparation for the meeting, and in the next class session, atudents are divided into small groups and given a topic for discussion. Each group must then choose from among themselves a chairperson, a recorder (or minute-taker), a reporter (or speaker), and an observer. During the ensuing discussion, which is just a vehicle for group interaction, the observer must watch group members' behavior and note observations. The group then agrees on the content and format of a written report to the instructor, and an oral report to the whole class at the following meeting. Each group member receives the mark for the reports given by that group's speakerand recorder. Another topic which may be introduced at this time is interviewing skills. Depending on the capabilities and interests of the class, role-playing exercises can be practised, with students taking turns being the interviewer and interviewee. Using actual job advertisements adds realism to the exercises. Once again, students will have been assigned reading material on interviewing before being required to do it, and the videotape provides feedback.

\section{The Final Sessions}

Iu one of the final sessions of the course, the last guest presenter arrives. This person should be a skilled speaker, for he or she comes to demonstrate, and later discuss, making the persuasive speech. This assignment is often the most difficult one for students, because here they must not only use the skills they have learned, but also their emotions. Putting feeling into a speech comes hard for many sutdents, so it is helpful for them now to observe and hear a practised orator give an impassioned address. At last they see how all that they have beet learning and practising can come together for an impressive performance. Experience shows that at this stage of the course, a good speech will be inspiring to students, whereas if it comes too early in the term, it will be discouraging.

In the closing week or two of the course, the time comes for the students to put on their final and most important performance - their last speech. Those class members who have attended regularly and kept up with assignments usually do well. They have learned how to organize a speech with careful planning, to illustrate it with visual aids, and to present it with feeling. Even the most shy and backward student who stays with the course and makes an effort will show marked improvement. But whatever stage student may have reached, making the final speech is an achievement for every one, and because speeches are videotaped, each can see his or her own performance and note the improvement. 
After the last speeches, or along with them, a social event to mark the end of the course is welcomed by members of the class. Because the class is mostly oral, students get to know, to empathize with, and to support one another. They realize they are $a 11$ in this experience together, either as listeners or speakers, and this draws the group together. A final get-together such as a pot-luck supper at someone's house, just puts the finishing touch on an experience most students will long remember. Not only have they learned new skill, but they have faced up to, and overcome, an old fear: speaking in public. Although in future course graduates may still be nervous when they must speak to groups, that nervousness will be teppered by the knowledge they have gained: ultimately, all can look forward to dealing more effectively with business, professional, or social situations requiring public speaking. This is an achievement indeed.

Betty Urquhart graduated from the University of British Columbia with majors in English, French and German, and in addition holds a professional teaching certificate. She has had extensive experience teaching adult students on both secondary and post-secondary levels, and presently is a Business Communications Instructor at Fraser Valley College, Chilliwack, B.C.

\section{A CUMULATIVE AND CO-OPERATIVE APPROACH TO WRITING DEVELOPMENT IN A FORESTRY FACULTY}

\section{M.T. (Jean) Dohaney}

When faculty members in Forest Resources, a department within the Faculty of Forestry at the University of New Brunswick, made the decision to commit their Department to a program of "in-house" written communication, they were cognizant of the need to integrate this program in some manner with their existing curriculum. They realized that the course or courses in communication should not be perceived by the students as being peripheral to their central course load. They also realized that it would take more than one semester of work to bring the students up to the professional level of writing that the Department desired.

This decision on "in-house" writing was made in the mid-seventies and it was made for two reasons:

1. Complaints from employers that the graduating students did not have sufficient skills in writing to write effective reports, proposals, and letters and

2. An awareness that an increased emphasis on forest management practices both within the Department and in the market place was demanding higher levels of writing than previously needed. An "in-house" program was chosen because of the unique structure of the program.

The program design was structured so that it would be both a cumulative and a co-operative approach. The design was cumulative in that students up-grading in writing skills was to begin in their second year with a three credit hour course in functional writing. This course was to be followed by a technical report to be written in the third year and another technical report to be written in the fourth year. In fifth year, the writing skills growth was to culminate in the presentation of a senior thesis.

The design was co-operative in that each faculty member evaluated the reports for content and the writing instructor evaluated them for writing. Each faculty member took responsibility for topics which were in his area of expertise. Just as the second year course was the sole responsibility of the writing instructor, the fifth year thesis was the sole responsibility of the $f$ aculty member whose area of expertise was covered by the topic of the thesis. Here, the writing instructor acted as a resource person only, aiding students with specific problems, such as how to place a visual effectively, or how to arrange an appendix so that it not only conforms to Forestry format, but is also convenient for the reader.

\section{CHARACTERISTICS OF FOR 2901}

This course covers basic writing skills, abstracting techniques, practice in researching, elements of the formal proposal, elements of the formal report and introduction to writing the journal article. The students themselves are responsible for upgrading their "basics." This is done through a programmed learning approach and accountability is arranged for 